\title{
Uncontrolled diabetes mellitus due to gastroparesis diabeticorum: treatment with metoclopramide
}

\author{
ERIK E. MULS \\ M.D. \\ GERARD F. LAMBERIGTS \\ M.D. \\ Department of Internal Medicine, Endocrine Unit, A.Z. St Jan, Ruddershove, \\ B-8000 Brugge, Belgium
}

\begin{abstract}
Summary
A case is reported of uncontrolled diabetes mellitus due to gastroparesis diabeticorum in which treatment with metoclopramide restored diabetic control. Diagnostic, pathological and therapeutic aspects of diabetic gastroparesis, which is thought to reflect autonomic neuropathy involving the gastrointestinal tract, are discussed.

\section{Introduction}

Uncontrolled diabetes mellitus may be caused by diabetic gastroparesis, i.e. gastric atony and delayed emptying. This can occur without obvious alimentary symptoms. A patient is described in whom metoclopramide treatment improved gastric emptying and restored diabetic control.
\end{abstract}

\section{Case report}

A 78-year-old woman with a maturity-onset diabetes of 21 years' duration was admitted to the hospital after a fortnight of severe daily hypoglycaemic episodes. She had lost $30 \mathrm{~kg}$ in one year. Gastrointestinal complaints were absent except for one episode of watery diarrhoea on the day before admission. On examination the abdomen was normal. She had postural hypotension and resting tachycardia (100 beats/min). Signs of peripheral sensorimotor neuropathy were present. She had no retinopathy, nephropathy, sweating abnormalities, or urinary bladder dysfunction. The insulin dosage was reduced from 36 to 22 units daily, but her diabetes was still poorly controlled and hypoglycaemic episodes recurred.

A radiological examination of the gastrointestinal tract showed diminished oesophageal peristaltic waves, gastric food residues, dilatation of the stomach with decreased peristalsis and with barium retention for more than $24 \mathrm{hr}$ (Fig. 1). The transit time of the contrast medium through the small intestine was prolonged. Gastroduodenoscopy revealed no pyloro-duodenal obstruction. Electro- myography showed the presence of peripheral neuropathy. The postural hypotension and the resting tachycardia had suggested autonomic neuropathy involving the cardiovascular system. This was confirmed by measuring the immediate heart rate response to standing as described by Ewing et al. (1978): the electrocardiographic $R-R$ interval ratio at beat $30 v$. beat 15 after standing was 0.95 in the patient, whereas diabetics without autonomic neuropathy have a $30: 15 \mathrm{R}-\mathrm{R}$ interval ratio of $\geqslant 1.03$.

These data led to the diagnosis of gastroparesis diabeticorum causing the worsening of diabetic control in a patient with peripheral and autonomic neuropathy. Treatment was instituted with oral metoclopramide in a dosage of $10 \mathrm{mg}, 30 \mathrm{~min}$ before each meal. The insulin regimen of 22 units daily was not changed. Diabetic control improved and no further hypoglycaemic episode occurred during the following months.

X-ray control (Fig. 2) during the fifth week of metoclopramide therapy showed considerable improvement, although complete gastric emptying of the barium still required $7 \mathrm{hr}$ (compared with more than $24 \mathrm{hr}$ before treatment).

\section{Discussion}

Uncontrolled diabetes mellitus may be due to irregular food absorption caused by gastric atony and delayed emptying of the stomach (gastroparesis diabeticorum). This worsening of diabetic control can occur in the absence of gastrointestinal complaints. The usual clinical manifestations are nausea, vomiting, vague abdominal complaints or anorexia. Bezoar formation can occur. Gastroparesis should also be suspected in the diabetic with unexplained weight loss, particularly if neuropathy involving other systems exists.

Radiological investigation is a readily available but relatively insensitive diagnostic method. Solid residue in the stomach at the beginning of the 

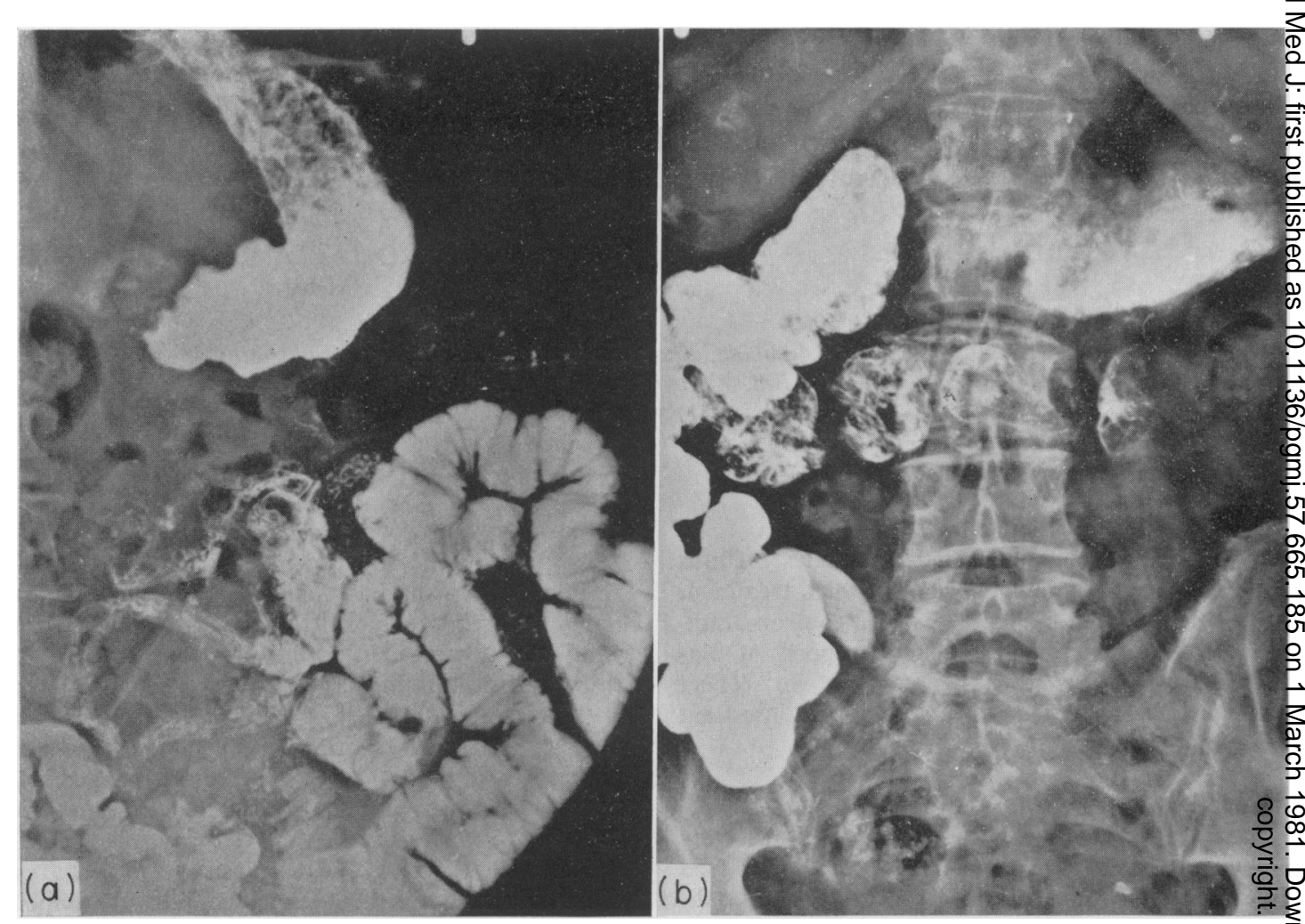

FIG. 1. Before the administration of metoclopramide, gastrointestinal radiological examination shows marked barium retention after $5 \mathrm{hr}$ (a) and after $24 \mathrm{hr}(\mathrm{b})$.

examination, decreased peristalsis with delayed gastric emptying and duodenal bulb atony are the principal radiological signs (Gramm, Reuter and Costello, 1978). Endoscopy should be done to exclude pyloro-duodenal obstruction. Gastric scintiscanning is a more accurate way to study gastric emptying. Using a double isotope scintiscanning technique, which differentiates between solid and liquid emptying, Campbell et al. (1977) showed gastric stasis to be present in all 3 patients with diabetic autonomic neuropathy and symptoms of gastroparesis although impaired gastric emptying was recognized radiologically in only one patient.

The delay in gastric emptying has been attributed to vagal damage occurring as part of a more generalized autonomic neuropathy (Wooten and Meriwether, 1961). Diabetics with symptoms of autonomic neuropathy have an impaired vagallymediated acid secretion in response to insulininduced hypoglycaemia but they have normal parietal cell function (Hosking et al., 1975). Surgical vagotomy, however, has no effect on the pattern of gastric emptying in non-diabetics when measured with the scintiscanning technique (Heading et at. 1975).

Pathological data concerning diabetics with gastroparesis are scarce. Duchen et al. (1980) recenty reported post-mortem studies of the autonomic nervous system in 5 insulin-dependent diabeties with peripheral and autonomic neuropathy involving the gastrointestinal tract. There was a severe loss of myelinated axons and a marked excess of collagen î the vagus nerve of all patients studied. This confirn the earlier observation of myelin degeneration in the vagal nerves as well as in the peripheral nerves if diabetics by Kristensson et al. (1971). Howeves several other pathological lesions were found these patients such as distension and vacuolizatip of neurones in coeliac and other sympathetic ganglid. inflammatory changes in the autonomic ganglia and in or around unmyelinated nerve fibres, and focil hyaline degeneration in the visceral smooth musc These findings suggested to Duchen et al. that several different pathogenetic mechanisms may be involved in the development of autonomic neur $\overline{\text { D- }}$ pathy in diabetes. The ultrastructural analysis off 


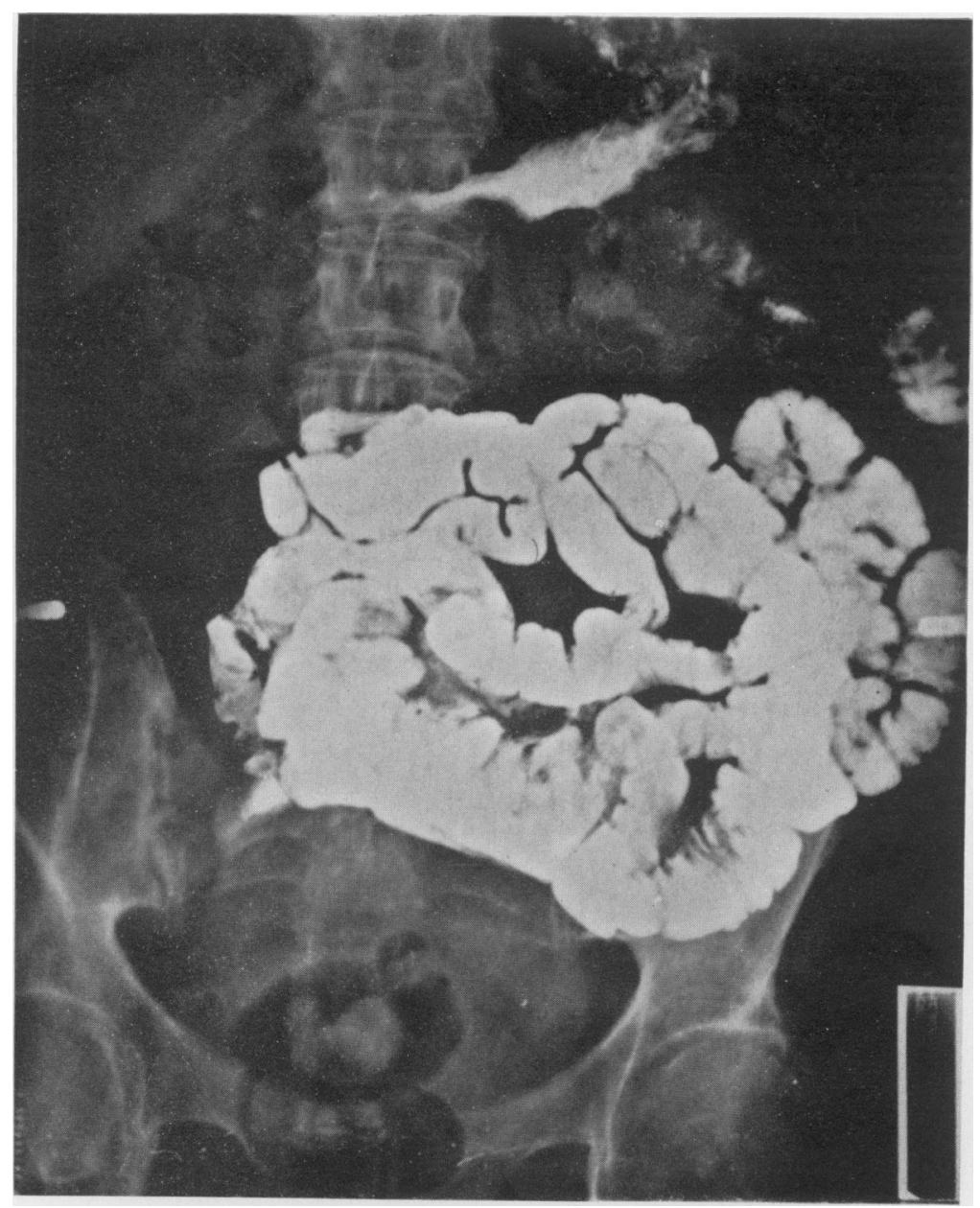

FIG. 2. Following metoclopramide therapy gastric emptying improved considerably, as shown 3 hr after the barium ingestion.

Auerbach's myenteric plexuses of the small intestine in ketonuric diabetic Chinese hamsters with radiological abnormalities comparable to those found in human gastroparesis diabeticorum showed degeneration of the distal unmyelinated axons (Diani et al., 1979).

Treatment of diabetic gastroparesis with pyloroplasty or partial gastrectomy, cholinergic agents or cholinesterase inhibitors has been disappointing (Wooten and Meriwether, 1961; Zitomer, Gramm and Kozak, 1968). More recently, however, a limited number of reports about metoclopramide therapy for diabetic gastroparesis have suggested an improvement in gastric emptying and diabetic control as evidenced in the present patient (Berkowitz, Metzger and Sturdevant, 1976; Campbell et al., 1977; Longstreth, Malagelada and Kelly, 1977; Braverman and Bogoch, 1978). The dopamine antagonist metoclopramide increases the frequency of type II gastric peristaltic contractions, speeding up the rate of gastric emptying (Longstreth et al., 1977). Metoclopramide may act by increasing the amount of acetylcholine released at the postganglionic nerve endings (Hay, 1977).

The authors conclude that gastroparesis diabeticorum should be considered in the patient with uncontrolled diabetes mellitus, even in the absence of abdominal symptoms, and that metoclopramide can be helpful in its treatment.

\section{References}

Berkowitz, D.M., Metzger, W.H. \& Sturdevant, R.A. (1976) Effect of metoclopramide in diabetic gastroparesis. Clinical Research, 24, 103A. 
Braverman, D. \& Bogoch, A. (1978) Metoclopramide for gastroparesis diabeticorum. Diabetes Care, 1, 356.

Campbell, I.W., Heading, R.C., Tothill, P., Buist, T.A., EwING, D.J. \& Clarke, B.F. (1977) Gastric emptying in diabetic autonomic neuropathy. Gut, 18, 462.

Diani, A.R., Grogan, D.M., Yates, M.E., Risinger, D.L. \& Gerritsen, G.C. (1979) Radiologic abnormalities and autonomic neuropathology in the digestive tract of the ketonuric diabetic Chinese hamster. Diabetologia, 17, 33.

Duchen, L.W., Anjorin, A., Watkins, P.J. \& Mackay, J.D. (1980) Pathology of autonomic neuropathy in diabetes mellitus. Annals of Internal Medicine, 92, 301.

Ewing, D.J., Campbell, I.W., Murray, A., Neilson, J.M. \& ClaRKe, B.F. (1978) Immediate heart-rate response to standing: simple test for autonomic neuropathy in diabetes. British Medical Journal, 1, 145.

Gramm, H.F., Reuter, K. \& Costello, P. (1978) The radiologic manifestations of diabetic gastric neuropathy and its differential diagnosis. Gastrointestinal Radiology, 3, 151.

HAY, A.M. (1977) Pharmacological analysis of the effects of metoclopramide on the guinea-pig isolated stoma承. Gastroenterology, 72, 864.

Heading, R.C., Tothill, P., Mcloughin, G.P. \& ShefßMAN, D.J. (1975) Effects of gastric surgery in differential emptying of solid and liquid components of the gastorc contents. British Journal of Surgery, 62, 659.

Hosking, D.J., Moody, F., StewarT, I.M. \& Atkinson, (1975) Vagal impairment of gastric secretion in diabeetic autonomic neuropathy. British Medical Journal, 2, 588

Kristensson, Y., Nordborg, C., Olsson, Y. \& Sourand暦, P. (1971) Changes in the vagus nerve in diabetes mellityS, Acta pathologica et microbiologica scandinavica, 79A, 684.

Longstreth, G.F., Malagelada, J.R. \& Kelly, K. (1977) Metoclopramide stimulation of gastric motility and emptying in diabetic gastroparesis. Annals of Intermal Medicine, 86, 195.

Wooten, R.L. \& Meriwether, T.W. (1961) Diabetic gastefic atony: a clinical study. Journal of the American Medieal Association, 176, 1082.

ZiTOMER, B.R., GrAMM, H.F. \& KozAK, G.P. (1968) Gastivic neuropathy in diabetes mellitus: clinical and radiologic observations. Metabolism, 17, 199. 